Таким образом, эффективное использование профессиональных качеств компетности в различных методов исследования и средств обучения в социальной активности педагога, которые в настоящее время сосредоточены на обучении, мышлении и самообучении, имеют важное значение в современном учебном процессе.

\section{Список литературы}

1. Аллак, Ж. Вклад в будущее: приоритет образования / Ж. Аллак. - М.: 1999.
2. Богуславский, М.В. ХХ век российского образования / М.В. Богуславский. - М.: 2002.

3. Гуревич, П.С. Психология и педагогика / П.С. Гуревич. - М.: 2005.

4. Зимняя, И.А. Педагогическая психология / И.А. Зимняя. - М.: Логос, 2004.

5. Киященко, Н.И. Стратегия образования в XXI веке / Н.И. Киященко. - М.: 2001.

6. Кравченко, А.И. Психология и педагогика / А.И. Кравченко. - М.: Проспект, 2007.

\title{
ОСОБЕННОСТИ РАЗВИТИЯ ПОЗНАВАТЕЛЬНЫХ ПРОЦЕССОВ ПОДРОСТКОВ
} ПОКОЛЕНИЯ Z

\section{АННОТАЦИЯ}

Дутко Юлия Александровна магистр психологии, педагог-психолог, ГБОУ Школа №2044

DOI: $10.31618 / E S U .2413-9335.2019 .3 .64 .231$

В статье формулируется основная цель - выявление особенностей познавательных процессов подростков поколения Z через сравнение с познавательными процессами подростков другого культурологического периода. Полученные результаты могут быть полезными для понимания закономерностей личностного развития современного ребенка и, соответственно, для развития психологопедагогической и педагогической науки и практики, в том числе в области методик обучения и воспитания.

\section{ANNOTATION}

The article formulates the main goal - to identify the features of cognitive processes of adolescents of generation $\mathrm{Z}$ through comparison with the cognitive processes of adolescents of another cultural period. The results can be useful for understanding the laws of personal development of the modern child and, accordingly, for the development of psychological, pedagogical and pedagogical science and practice, including in the field of methods of training and education.

Ключевые слова: Познавательные процессы, поколения Z, цифровое поколение, подростки, цифровизация, память, внимание, мышление, интеллект.

Keyword: Cognitive processes, generation Z, digital generation, adolescents, digitalization, memory, attention, thinking, intelligence.

В настоящее $\begin{array}{r}\text { Введение } \\ \text { время важнейшими }\end{array}$ компонентами жизни являются средства цифровых коммуникаций. Их появление радикально изменило окружающий мир, образовательную среду и самих людей. Поколение, родившееся в начале 2000-х годов, получило название «поколения Z». Это дети, развитие и социализация которых проходит в условиях глобального распространения цифровых технологий. Согласно культурно-исторической теории деятельности, если компоненты цифровой реальности становятся для современного ребенка важнейшими средствами деятельности и общения, это должно находить свое отражение через процессы интериоризации в развитии высших психических функций: внимания, памяти, мышления, а также в структуре личности человека в целом.

На сегодняшний день, несмотря на то, что значительная часть психологических исследований посвящена изучению познавательных процессов, социокультурный аспект развития познавательных процессов подростков, относящихся к разным культурологическим периодам, остается малоизученной и дискуссионной проблемой, чем обусловлена актуальность данного исследования.

Новизна исследования состоит в том, что выявлена специфика познавательных процессов у подростков цифрового поколения, с учетом которой можно внести адекватные изменения в методиках обучения и воспитания.

Полученные результаты могут применяться в образовательной сфере: в психологическом сопровождении и коррекции личностного развития учащихся подросткового возраста; при разработке учебных программ и образовательных профилей; могут быть использованы для разработки тренинговых программ по работе с родителями детей, а также как материал для родительских конференций, круглых столов и дискуссионных мастерских, проводимых с целью повышения у специалистов и родителей их психологической компетентности.

\section{Методология и основные теоретические положения.}

Методологической основой исследования стали общие положения диалектического материализма, исходящие из представлений о культурно-исторической обусловленности человеческой психики, формирование психических 
процессов под влиянием социальных факторов, и опосредованном характере психических процессов [Маркс, 1955, 25]. В нашей работе ведущая роль в развитии познавательных процессов принадлежит социокультурной среде.

Также, в своей работе мы опирались на идею Л.С. Выготского о том, что согласно культурноисторической теории деятельности, высшие психические функции человека имеют социальную природу [Выготский, 2005, 385]. Если компоненты цифровой реальности становятся для современного ребенка важнейшими средствами деятельности и общения, то это находит свое отражение через процессы интериоризации в развитии высших психических функций. Компоненты цифровой реальности интериоризируются в ВПФ - значит, меняются и сами познавательные процессы, что позволяет нам выдвинуть предположение, что у подростков поколения Z существует специфика познавательных процессов.

Для нашего исследования стала значимой идея Нила Хоува и Уильяма Штрауса о том что, ценности поколений формируются под влиянием условий воспитания и социокультурной среды, оказывая существенное влияние до 12-14 лет [Howe, 1991, 57]. Данное положение определяет возраст респондентов в нашем исследовании, так как именно в 12-14 происходит вращивание социокультурной среды в человека.

\section{Гипотезы и их обоснование.}

Общая гипотеза: по сравнению с подростками поколения Y у подростков поколения Z развитие познавательных процессов имеет свою специфику.

- объем памяти имеет высокие показатели кратковременной памяти и низкие показатели долговременной; Современному ребенку, имеющему возможность в любое время найти нужную информацию нет смысла хранить ее в долговременной памяти.

- наглядно-образное мышление преобладает над словесно-логическим; Словесно-логическое мышления характеризуется не только построением логических операций, но и грамотным владением речи и умением использовать ее, мы полагаем, что это обусловлено тем, что у подростков поколения $\mathrm{Z}$, прошедшие социализацию в условиях цифровизации, не могут использовать речевые конструкции, так как делали это раньше. Это связано с тем, что современный подросток в общении предпочитает невербальные формы.

- свойства внимания характеризуются низкими показателями устойчивости и продуктивности и высокими показателями переключаемости; Устойчивость и продуктивность внимания у таких детей уменьшается в десятки раз по сравнению с предыдущим поколением - они не могут длительное время удерживать внимание на предмете или какой-либо деятельности из-за присущей им многозадачности и клиповости мышления.

- невербальный интеллект преобладает над вербальным интеллектом; Современный подросток воспринимает информацию визуально, так как меняется вид деятельности от вербальной к невербальной.

\section{Методики для сбора информации и их обоснование.}

Отбор методик нами осуществлялся исходя из следующих критериев: соответствие возрасту респондентов; адаптированность для детей как поколения Z, так и детей других поколений: наиболее распространенные и известные методики (валидность и надежность); соответствие с методологией и целями исследования. Нами была сформулирована авторская анкета, определяющая принадлежность подростков к «цифровому поколению».

Так же, в работе для сбора информации были использованы следующие методики [Римский , 1995]: методика «Заучивание 10 слов» А.Р. Лурия, методика для оценки интеллекта Д.Векслера, методика «Выделение существенных признаков» С.Я. Рубинштейна, методика Дж. Равена, методика «Корректурные пробы» Б. Бурдона.

\section{Описание выборки.}

В исследовании приняли участие 80 подростков, относящихся к двум разным культурологическим периодам. Группа 1. Подростки поколения Z (рожденные после 2000 гг.), 40 человек. (20 мальчиков и 20 девочек) Группа 2. Подростки поколения Y (рожденные до 2000 гг.), 40 человек. (20 мальчиков и 20 девочек).

Средний возраст респондентов - 13-14 лет. Исследование познавательных процессов подростков поколения Z проводилось в ГБОУ Школа № 2044, результаты исследований подростков другого культурологического периода были взяты из кандидатских диссертаций Российской государственной библиотеки. Возраст испытуемых был выбран в соответствии с возрастной периодизацией [Эльконин, 1960, 107], обозначающей возрастной период 11-15 лет как подростковый возраст.

\section{Описание результатов.}

Согласно результатам математической статистики [Ермолаев, 2004, 126], проведенным Ткритерием Стьюдента и U-критерием Манн-Уитни, оценивая полученные данные, мы обращались в своей работе к результатам на уровне значимости $\mathrm{p}<0,01$.

Так в исследовании словесно-логического мышления между группой подростков цифрового поколения и подростков другого культурологического периода словесно-логическое мышление статистически достоверно ( $\mathrm{Z}=2,43896$; $\mathrm{p} \leq 0,01)$ выше в группе подростков поколения $\mathrm{Y}$, как и мальчиков, так и девочек; Также, было установлено, что различия между результатами исследования наглядно-образного мышления обеих групп испытуемых статистически значимы (Z=7,41595; $\mathrm{p} \leq 0,01)$, следовательно, показатели наглядно-образного мышления у подростков поколения Z выше, чем у подростков поколения Y; В изучении свойств внимания были выявлены статистически значимые различия по уровню переключаемости $(\mathrm{Z}=3,7878 ; \quad \mathrm{p} \leq 0,01) \quad$ и 
устойчивости $(\mathrm{Z}=2,14117 ; \mathrm{p} \leq 0,01)$, по уровню продуктивности различия не были установлены, так подростки поколения $\mathrm{Z}$ имеют более низкие показатели по диагностики устойчивости и более высокие показатели по диагностики переключаемости, чем подростки поколения Y. Также, было установлено, что различия между результатами обеих групп испытуемых по объему долговременной памяти статистически значимы $(\mathrm{Z}=1,93204 ; \mathrm{p} \leq 0,01)$ - подростки имеют более низкие показатели по объему долговременной памяти, по объему кратковременной памяти статистически значимых различий нет. Также стоит отметить, что у подростков поколения Z преобладает кратковременная память; В исследовании интеллекта было установлено, что в некоторых показателях существуют статистически значимые различия между результатами обеих групп испытуемых по уровню вербального и невербального интеллекта, так у подростков более высокие показатели по субтестам: высокие показатели по субтестам «Осведомленность» $(\mathrm{Z}=-$ 6,50895; $\mathrm{p} \leq 0,01)$, «Кубики Кооса» ( $Z=-13,7063$; $\mathrm{p} \leq 0,01)$, «Складывание фигур» $(\mathrm{Z}=1,32692 ; \mathrm{p} \leq 0,01)$ , «Шифровка» $(\mathrm{Z}=-3,54836 ; \mathrm{p} \leq 0,01)$, «Лабиринты» $(\mathrm{Z}=3,48047 ; \mathrm{p} \leq 0,01)$ и «Невербальный интеллект» $(Z=0,529469 ; \quad p \leq 0,01)$; низкие показатели по субтестам «Арифметический» (Z=-14,3886; $\mathrm{p} \leq 0,01), \quad$ «хходство» $(\mathrm{Z}=3,48967 ; \quad \mathrm{p} \leq 0,01)$ «Словарный» $(\mathrm{Z}=4,5937 ; \mathrm{p} \leq 0,01)$, «Вербальный интеллект» $(\mathrm{Z}=6,79534 ; \mathrm{p} \leq 0,01), \quad$ сходство по субтестам «Понятливость», «Повторение цифр», «Недостающие детали», «Последовательные картинки» и «Общий интеллект».

Проанализировав результаты исследования, мы можем сделать вывод о том, что:

- словесно-логическое

мышление характеризуется не только построением логических операций, но и грамотным владением речи и умением использовать ее, мы полагаем, что это обусловлено тем, что у подростков поколения $\mathrm{Z}$ не могут использовать речевые конструкции. Это связано с тем, что современный подросток в общении предпочитает невербальные формы (сообщения в социальных сетях), что подтверждено результатами авторской анкеты, соответственно другие формы передачи информации остаются не развитыми.

- наглядно-образное зрительным представление образов и ситуаций, практической деятельностью человека с предметом, этот вид мышления у подростков поколение $\mathrm{Z}$ более развит, в связи с их, опосредованной цифровыми средствами, деятельностью - их развитие проходит в условиях кибер-среды, которая предоставляет наглядный и понятный материал - любая информация в телефоне, планшете, компьютере представляется им в графической форме.

- у подростков поколения Z наиболее выражены трудности в устойчивости внимания, высокая истощаемость. Малое количество общих просмотренных букв и ошибочно отмеченные и пропущенные буквы свидетельствуют о недостаточной концентрации внимания и объеме внимания. Но по показателю переключаемости эти дети более развиты, так как современная социальная ситуация требует от них многозадачности. Продуктивность внимания у подростков двух поколения находится на одном уровне, что говорит нам о том, что, несмотря на колебания в устойчивости и переключаемости продуктивность у таких детей одинаковая, но разные способы овладения ею.

- различия в долговременной памяти обусловлены тем, что подростки поколения Z перегружены массивом информаций, преподнесенный им Интернет-Сетью, такие дети не в состоянии запомнить такой массив информации, в век цифровых технологий подросток в любое время может зайти в телефон и найти интересующую его тему, в следствии чего у цифрового поколения наблюдается ограниченный объем долговременной памяти, что говорит о неспособности пользоваться приемами долгосрочного запоминания и воспроизведения.

- в исследовании кратковременной памяти статистически значимых различий нет, это связано с тем, что подростки поколения $\mathrm{Z}$ и подростки поколения Y имеют соответствующий возрастной норме уровень запоминания, т.е. могут быстро запомнить и воспроизвести полученную ими информацию, так как особой специфики в изменившихся условиях не наблюдается. Стоит отметить, что лучше запоминается ими материал, который многократно был повторен, связанный уже с имеющимися на данный момент знаниями и представленный визуально.

- в ходе исследования интеллекта у подростков поколения Z были выявлены более высокие показатели по субтестам: «Общая осведомленность», «Кубики Кооса», «Складывание фигур», «Кодирование», «Лабиринт». Мы можем объяснить это, тем что у подростков поколения $\mathrm{Z}$ по сравнению с предыдущими поколения есть доступ к огромному массиву информации, который ежедневно поступает из Интернета и СМИ, что не может не отразится на кругозоре этих детей развито конструктивное мышление, вследствие высокого уровня восприятия, выработанного за счет взаимодействия с средствами коммуникации; развита высокая многозадачность - современные дети вынуждены одновременно выполнять ряд зачет, за счет чего повышается уровень переключаемости, вследствие распределения внимания и работоспособности; развиты зрительно-двигательные рефлексы за счет их постоянного контакта с телефоном, где она следят за курсором мышки, игрой на телефоне и т.д.

- в ходе проведения исследования также было выявлено, что подростки поколения Z отличаются более низкими статистически значимыми показателями по субтестам: «Арифметический», «Сходство - аналогии», «Словарный». Это связано с тем, что у подростка поколения $\mathrm{Z}$ слабо развиты способности к устному 
счету, умению быстро ориентироваться в условиях задачи, так как такой подросток в повседневной жизни для вычислений использует разработаны программные обеспечения, которые сами решают примеры, уравнения и даже задачи; слабо развита способность к обобщению, выделению существенных признаков - это проявляется в неспособности вычленить из книги главную мысль; слабо развит словарный запас, так как современный подростков большую часть времени проводит в Интернет-Сети и общается при помощи сокращений.

Также у подростков поколения Z выявлены статистически значимые различия в уровне невербального и вербального интеллекта, связанные, во-первых, с вышеперечисленными фактами, во-вторых, с тем, что современные ребенок на сегодняшний день использует невербальные средства коммуникации, он опосредует общение средствами цифровых коммуникаций - пишет сообщения в социальных сетях, любая деятельность носит невербальный характер.

В ходе проведения исследования не было выявлено различий между подростками двух поколения по субтестам: «Понятливость» и «Повторение цифр», так как особой специфики в изменившихся условиях не наблюдается, данные виды памяти не опосредуются цифровыми технологиями.

\section{Заключение}

Данная работа посвящена изучению особенностей развития познавательных процессов у подростков поколения Z.

В соответствии с целью данной работы, были проанализированы подходы различных философов и ученых к понятию «познавательные процессы», определено понятие «поколение Z», выделены особенности подросткового возраста и познавательной сферы подростков цифрового поколения и подростков другх
и культурологических периодов.

В философском понимании в структуре познавательного процесса выделялись чувственный и рациональный уровни. На чувственном уровне познавательный процесс являлся обобщением чувственных данных. На рациональном - разум считается единственным источником знания. Продолжая традиции античных философов, к проблеме развития познавательных процессов обращались многие отечественные и зарубежные ученые и психологи. Одни считали познавательные процессы как «интеллектуальный рост человека от рождения к взрослости», другие понимали как переход из внешне - предметной деятельности во внутренний способ мышления, третьи - как результат развивающего обучения, т.е. как искусственный процесс.
Подростковый период - это сензитивный период развития познавательных процессов. Важно не упустить его. Поэтому особенный интерес представляют подростки цифрового поколения.

Поколение, родившееся в начале 2000-х годов, получило название «цифрового поколения» или «поколения Z». Это дети, развитие и социализация которых проходит в условиях глобального распространения цифровых технологий.

Согласно культурно-исторической теории деятельности, если компоненты цифровой реальности становятся для современного ребенка важнейшими средствами деятельности и общения, это должно находить свое отражение через процессы интериоризации в развитии высших психических функций.

Подводя итог, можно сказать, что в предпринятом исследовании проведен генезис понятия «познавательные процессы», описаны психологические особенности познавательных процессов личности подростка поколения $\mathrm{Z}$. Проведенное исследование убедительно показало, что у подростков цифрового поколения основные отличия связаны с многозадачность и невербальными механизмами познавательных процессов.

Так недостатки мышления проявляются в низкой способности к обобщению материала, операциям синтеза и анализа, но наглядно образное мышление является ведущим. Ограничен объем долговременно памяти, снижена долгосрочность запоминания, но кратковременная память находится на надлежащем уровне. Внимание неустойчивое и носит непроизвольный характер, но продуктивность и переключаемость внимания соответствует норме.

Следовательно, наша гипотеза подтвердилась частично. Мы делаем вывод, что глобализация цифровых технологий оказала серьезное влияние на личность подростка, что отражается в особой специфике формирования познавательных процессов. Данный феномен, несомненно, вызывает интерес и требует дальнейшего исследования.

\section{Список литературных источников}

1. Выготский Л.С. Психология развития человека. - М., 2005. - 1136 с.

2. Ермолаев О.Ю. Математическая статистика для психологов. - М., 2004. - 336 с.

3. Маркс К., Энгельс Ф. Сочинения. - М., 1955. $-650 \mathrm{c}$.

4. Римский Р.Р. Альманах психологических тестов. - М., 1995. - 400 с.

5. Эльконин Д.Б. Детская психология. - М., 1960. - 384 c.

6. Howe N., Strauss W. Generations: The History of America's Future, 1584 to 2069. New York, 1991. - p. 300. 